\title{
Doenças respiratórias em bezerros na região sul do Rio Grande do Sul: estudo retrospectivo de 33 surtos $^{1}$
}

\author{
Nathalia D. Assis Brasil², Fabiane L. Hinnah ${ }^{3}$, Letícia Fiss² ${ }^{2}$, Eliza S.V. Sallis ${ }^{4}$, Fabiane \\ B. Grecco ${ }^{4}$, Silvia R.L. Ladeira ${ }^{5}$, Clairton Marcolongo-Pereira ${ }^{2}$ e Ana Lucia Schild ${ }^{5 *}$
}

\begin{abstract}
Assis-Brasil N.D., Hinnah F.L., Fiss L., Sallis E.S.V., Grecco F.B., Ladeira S.R.L., Marcolongo-Pereira C. \& Schild A.L. 2013. [Respiratory diseases in calves in southern Rio Grande do Sul: study of 33 outbreaks.] Doenças respiratórias em bezerros na região sul do Rio Grande do Sul: estudo de 33 surtos. Pesquisa Veterinária Brasileira 33(6):745-751. Laboratório Regional de Diagnóstico, Faculdade de Veterinária, Universidade Federal de Pelotas, Campus Universitário s/n, Pelotas, RS 96010-900, Brazil. E-mail: alschild@terra.com.br

Thirty-three outbreaks involving pneumonia in young cattle diagnosed in the area of influence of the Regional Diagnostic Laboratory (LRD) of the Veterinary School of the Federal University of Pelotas (UFPel) between 2000 and 2011 were studied. Eighteen outbreaks (54.54\%) were diagnosed in dairy breeds and Jersey or Holstein and 13 outbreaks (39.39\%) in beef cattle or crossbred beef cattle. Morbidity ranged from $0.06 \%-100 \%$ and mortality was $0.06 \%$ to $34.61 \%$. The disease occurred in all seasons of year and was more frequent in calves aged 1-3 months (11 outbreaks). Seven outbreaks occurred in cattle between 4-6 months, seven between 6-12 months and six outbreaks occurred in calves 1-30 days. Bovine respiratory disease due to infection with bovine respiratory syncytial virus (BRSV) was more frequent in beef cattle breeds with eight outbreaks (44.44\%); six outbreaks of this disease occurred in calves of dairy breeds (33.33\%). The diagnosis was confirmed by immunohistochemistry in seven cases. The main clinical signs were characterized by dyspnea, weight loss, lethargy, tremors, bruxism, dehydration, rapid and noisy breathing, coughing, serous or mucopurulent nasal discharge, recumbency and death. Gross lesions were characterized by dark red areas of consolidation, edema and emphysema in cranioventral regions of the apical and cardiac lung lobes or diffuse interstitial pneumonia, edema and emphysema. Histologically, lung lesions were variable. Diffuse bronchopneumonia necrotizing with marked hyperplasia of type II pneumocytes and alveolar and interstitial edema was observed in 15 cases. The results of this study demonstrate that pneumonia is an important cause of economic loss in young cattle in the area of influence of the LRD and that enzootic pneumonia due to BRSV infection is important in both beef cattle and milk cattle regardless of husbandry systems.
\end{abstract}

INDEX TERMS: Calves, enzootic pneumonia, bovine respiratory syncytial virus, bronchopneumonia, interstitial pneumonia.

\footnotetext{
${ }^{1}$ Recebido em 18 de março de 2013.

Aceito para publicação em 28 de maio de 2013.

${ }^{2}$ Pós-Graduando em Veterinária, Faculdade de Veterinária, UFPel, Campus Universitário s/n, Pelotas, RS 96010-900, Brasil.

${ }^{3}$ Graduando de Medicina Veterinária, Faculdade de Veterinária, UFPel, Pelotas, RS. Bolsista de Iniciação Científica do CNPq.

${ }^{4}$ Docentes do Departamento de Patologia Animal, Faculdade de Veterinária, UFPel, Pelotas, RS.

${ }^{5}$ Médicos Veterinários do Laboratório Regional de Diagnóstico (LRD), UFPel, Pelotas, RS. *Autor para correspondência: alschild@terra.com.br
}

RESUMO.- Foram estudados 33 surtos de pneumonia em bovinos jovens na área de influência do Laboratório Regional de Diagnóstico (LRD) da Faculdade de Veterinária da Universidade Federal de Pelotas (UFPel) entre os anos de 2000 e 2011. Foram diagnosticados 18 surtos de pneumonia $(54,54 \%)$ em bovinos de raças leiteiras, Holandês ou Jersey e 13 surtos $(39,39 \%)$ em gado de corte ou cruzas de gado de corte. A morbidade variou entre $0,06 \%-100 \%$ e a mortalidade foi de $0,06 \%-34,6 \%$. A doença ocorreu igual- 
mente em todas as estações do ano e foi mais frequente em bezerros de 1-3 meses totalizando 13 surtos. Sete surtos ocorreram em bovinos entre 4-6 meses, sete entre 7-12 meses e seis surtos ocorreram em bezerros de 1-29 dias. Pneumonia enzoótica pela infecção pelo vírus sincicial respiratório bovino (BRSV) com lesões histológicas de broncopneumonia, pneumonia intersticial e presença de células sinciciais foi mais frequente em bovinos de raças de corte com dez surtos $(58,8 \%)$; seis surtos dessa enfermidade ocorreram em raças de leite $(35,2 \%)$. 0 diagnóstico foi confirmado por imuno-histoquímica em sete casos. Os sinais clínicos da maioria dos casos de pneumonia observados caracterizaram-se por dispneia, emagrecimento, apatia, tremores, bruxismo, desidratação, respiração ruidosa, tosse, corrimento nasal seroso ou mucopurulento, decúbito e morte. As lesões macroscópicas caracterizaram-se por presença de áreas de consolidação vermelho-escuras, edema e enfisema nas regiões crânio-ventrais dos lobos pulmonares cardíaco e apical ou pneumonia intersticial com distribuição difusa, edema e enfisema. Histologicamente, as lesões pulmonares eram variáveis. Broncopneumonia necrossupurativa difusa acentuada com hiperplasia de pneumócitos tipo II e edema intersticial e alveolar foi observada em 15 casos. Os resultados deste trabalho demonstram que as pneumonias são importantes causas de perdas econômicas em bovinos jovens na região de influência do LRD. Deve ser destacado que a pneumonia enzoótica devido a infecção pelo BRSV é importante tanto em bovinos de corte como de leite independente da forma de criação.

TERMOS DE INDEXAÇÃO: Bezerros, pneumonia enzoótica, vírus sincicial respiratório bovino, broncopneumonia, pneumonia intersticial.

\section{INTRODUÇÃO}

O complexo respiratório bovino, denominado, também, pneumonia enzoótica, é causado por um conjunto de agentes etiológicos dos quais o mais importante é o virus respiratório sincicial bovino (BRSV) (Fulton et al. 2009), seguido pelo virus da parainfluenza bovina (BPIV-3), virus da rinotraqueite infecciosa bovina (IBR), virus da diarreia viral bovina (BVDV), herpesvirus bovino-1 (BoHV-1) e adenovirus bovino A-D (BAdV-A-D) (Fulton et al. 2009). Infecções secundárias por bactérias como Mannheimia haemolytica, Pasteurella multocida, Histophilus somni e Mycoplasma bovis são frequentemente observadas (Snowder et al. 2006, Driemeier \& Moojen 2007, Fulton et al. 2009).

O complexo respiratório bovino é causa frequente de mortalidade de bezerros. Percentuais de 10\%-66\% de mortalidade devido a essa enfermidade em bezerros confinados têm sido encontrados no Canadá e percentuais de 44\%-67\% têm sido observados nos Estados Unidos (Gagea et al. 2006a). 0 transporte e a criação de bezerros em confinamento ampliam os fatores de risco ambiental e reforçam as causas predisponentes, que incluem: idade, estresse, alterações nutricionais e o estado imunológico dos animais (Snowder et al. 2006). Os fatores de risco ambiental abarcam: clima, temperatura ambiente, umidade, presença de partículas de poeira, lotação, ventilação e distância trans- portada (Snowder et al. 2006). Os fatores epidemiológicos compreendem: agentes microbianos, modo de transmissão, densidade parasitária, virulência, períodos de infecção, de latência e de transmissão (Snowder et al. 2006).

No Rio Grande do Sul (RS) um surto da doença foi descrito em bovinos de corte em regime extensivo sem associação com nenhum dos agentes secundários à doença (Driemeier et al. 1997). Em Alagoas (AL) a doença foi, também, diagnosticada em bezerros de raças leiteiras filhos de animais importados, que chegaram ao país, presumivelmente, já infectados pelo virus (Peixoto et al. 2000).

Apesar da vacinação e uso profilático de antibiótico a pneumonia enzoótica permanece sendo a causa mais importante de mortalidade de bezerros de corte durante os primeiros dois meses após a introdução no confinamento (Gagea et al. 2006a). Os custos para o tratamento da doença podem aumentar significativamente quando são considerados: aquisição de medicamentos, mão de obra, isolamento, aumento do tempo de alimentação, mortalidade e profilaxia (Snowder et al. 2006). Além disso, tem sido demonstrado que doenças respiratórias estão associadas à diminuição da qualidade da carcaça e há decréscimo significativo no ganho de peso de animais confinados (0,07-0,20 $\mathrm{kg} / \mathrm{animal} /$ dia) (Loneragan et al. 2001).

Em um levantamento das causas de morte em bovinos até um ano de idade recebidos no Laboratório Regional de Diagnóstico da Faculdade de Veterinária da Universidade Federal de Pelotas (LRD/UFPel) entre 2000-2011 foi observado que de um total de 220 bezerros $16,8 \%$ morreram em consequência de doenças respiratórias (Assis-Brasil et al. 2013).

O objetivo deste trabalho foi estudar a epidemiologia e a patologia dos surtos de pneumonias diagnosticadas em bezerros até um ano de idade verificando a etiologia dos casos de doenças respiratórias que ocasionaram a morte de bezerros na área de influência do LRD/UFPel.

\section{MATERIAL E MÉTODOS}

Foram revisados os protocolos de necropsia de bovinos com diagnóstico de doença respiratória recebidos no Laboratório Regional de Diagnóstico da Faculdade de Veterinária da Universidade Federal de Pelotas (LRD/UFPel) entre janeiro de 2000 e dezembro 2011. Foi incluído, também, o material de necropsias realizadas a campo por veterinários que enviaram material para exame histológico. Desses protocolos foram resgatados os dados epidemiológicos, sinais clínicos, lesões macroscópicas e histológicas e resultados de culturas bacterianas quando haviam.

Foram resgatados os blocos de parafina de cada caso para reavaliação histológica, considerando-se os diagnósticos morfológicos atribuídos a cada material pelo patologista responsável pelo caso. Em sete casos não havia blocos de parafina nos arquivos do LRD.

Os casos cujas lesões macroscópicas descritas no protocolo (broncopneumonia lobar afetando as regiões crâneo-ventrais pulmonares) associadas às lesões histológicas de broncopneumonia necrossupurativa ou pneumonia intersticial, sugestivas de infecção pelo BRSV que tinham este diagnóstico no protocolo foram submetidos à técnica de imuno-histoquímica streptavidina-biotina utilizando anticorpo policlonal anti-BRSV, (VMRD Inc., Pullman, WA), de acordo com a técnica utilizada por Flores 
et al. (2000). A imuno-histoquímica foi realizada, também, para detecção do vírus BPIV-3 (VMRD Inc., Pullman, WA. Os cortes foram desparafinizados e foi feito o bloqueio da peroxidase endógena com peróxido de hidrogênio 3\% diluído em metanol. As lâminas foram submetidas à digestão prévia com tripsina a $0,1 \%$ em banho-maria, ficando imersas em tampão citrato $(\mathrm{pH} \mathrm{6,0)} \mathrm{em}$ micro-ondas por 10 minutos na potência máxima (1300 W). Para o bloqueio de reações inespecíficas da avidina endógena foi utilizado soro fetal bovino a 1\%, clara de ovo e leite em pó desnatado a $5 \%$ em PBS. 0 anticorpo anti-BRSV e anti-BPIV-3 foram utilizados numa diluição de $1: 100$ por uma hora à $37^{\circ} \mathrm{C}$ e como cromógeno foi utilizado o diaminobenzidina (DAB). As lâminas foram contra-coradas com hematoxilina de Harris e montadas em entelan. No controle negativo o anticorpo primário foi substituído por PBS.

\section{RESULTADOS}

De um total de 306 necropsias de bovinos até um ano de idade examinados no Laboratório Regional de Diagnóstico da Faculdade de Veterinária da Universidade Federal de Pelotas (LRD/UFPel) entre janeiro de 2000 e dezembro de 2011, 220 tiveram diagnóstico conclusivo dos quais 33 (15\%) corresponderam às infecções respiratórias. Destes 33 casos, $16(48,4 \%)$ distribuíram-se entre pneumonias inespecíficas, pneumonia aspirativa e pneumonia verminótica. Dezessete $(51,5 \%)$ caracterizaram-se por lesões consistentes com pneumonia enzoótica.
Com relação à raça dos bovinos afetados 18 surtos de pneumonia $(54,5 \%)$ ocorreram em animais de raças leiteiras, Holandês ou Jersey e 13 surtos (39,3\%) ocorreram em gado de corte (raça pura ou cruzas) e em dois surtos a raça não constava nos protocolos. Em apenas um surto observado em bovinos de corte os animais eram confinados.

A morbidade variou de 0,06 a $100 \%$ e a mortalidade foi de 0,06 a $34,6 \%$. Os surtos ocorreram em todas as estações do ano com distribuição semelhante, sendo nove no inverno, dez na primavera, sete no outono e sete no verão. A doença ocorreu com maior frequência em bezerros de 1-3 meses totalizando 13 surtos. Sete surtos ocorreram em bovinos entre 4 e 6 meses, sete entre 7 e 12 meses e quatro surtos ocorreram em bezerros de 1-20 dias. Em dois casos não constava a idade dos bovinos afetados no protocolo, apenas a categoria bezerro. Em um surto foi mencionado que os bovinos haviam sofrido estresse pelo excesso de chuva uma semana antes do início dos sinais clínicos. Em pelo menos cinco casos os bovinos haviam sido desmamados antes do início dos sinais clínicos (Fig.1A). 0 resumo dos dados epidemiológicos está apresentado no Quadro 1.

Com relação a pneumonia enzoótica e/ou presença de lesões compatíveis com esta enfermidade dez surtos ocorreram em bovinos de raças de corte $(58,8 \%)$ e seis ocorreram em raças de leite $(35,2 \%)$. Em um surto a raça dos
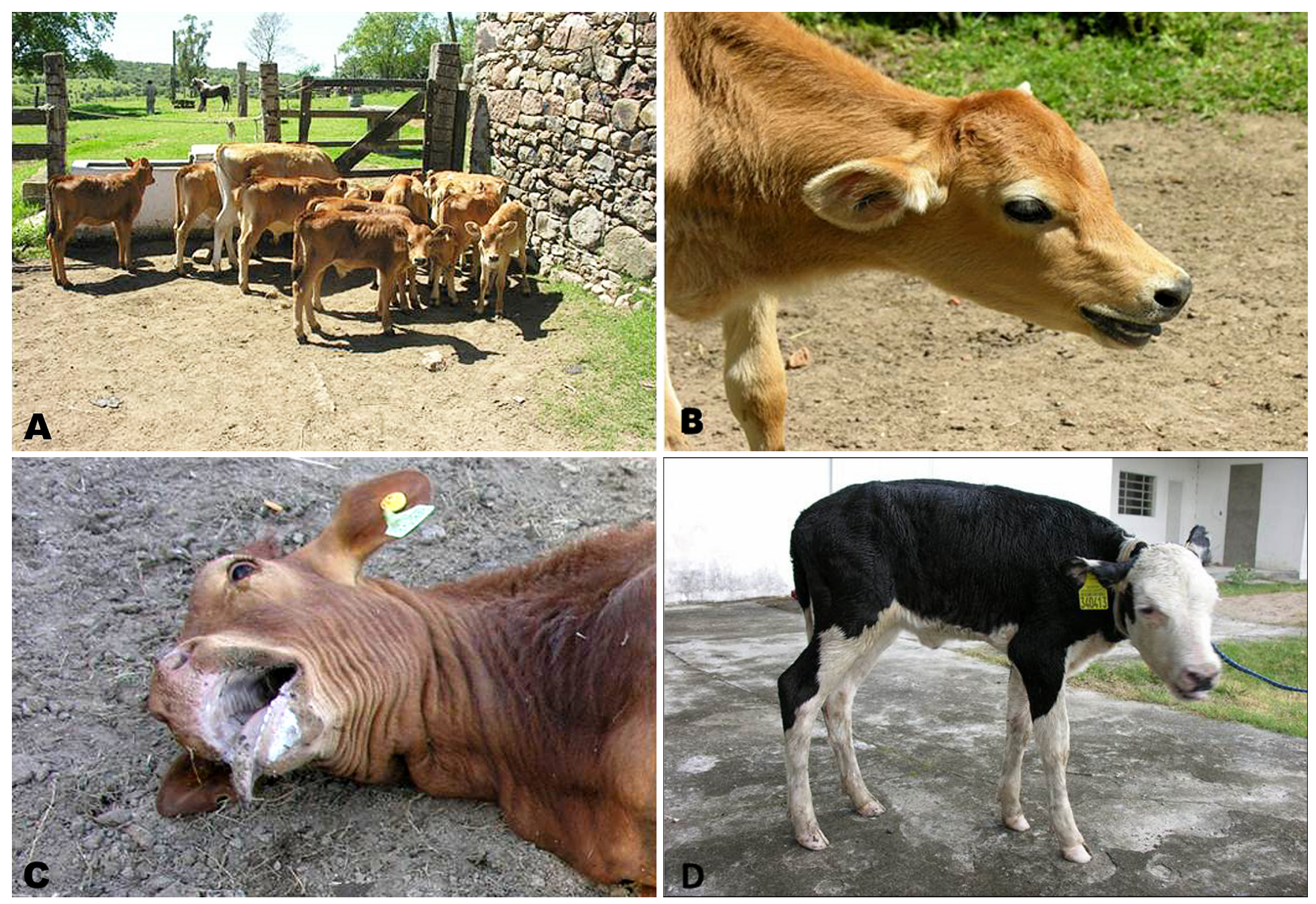

Fig.1. (A) Lote de bovinos desmamados que apresentaram sinais clínicos respiratórios. (B) Bezerro afetado apresentando dispneia evidenciada pelo pescoço estendido e protrusão da língua. (C) Bezerro com a boca aberta e salivação intensa evidenciando dispneia acentuada. (D) Bezerro apresentando dispneia e tosse evidenciados pela exposição da língua e arqueamento do dorso. 

Quadro 1. Epidemiologia dos surtos de pneumonia diagnosticados no Laboratório Regional de Diagnóstico da Universidade Federal de Pelotas, em bezerros até um ano de idade na região Sul do Rio Grande do Sul, entre 2000 e 2011

\begin{tabular}{|c|c|c|c|c|c|c|c|}
\hline Surto & Mês/Ano & Animais sob risco & Idade & Morbi dade & Morta lidade & Raça & Diag nóstico \\
\hline 1 & $12 / 2000$ & 45 & $1 \mathrm{~m}$ & $0,44 \%$ & $0,44 \%$ & Cruza (corte) & $\mathrm{PE}+$ \\
\hline 2 & $01 / 2001$ & 1800 & $1 \mathrm{~m}$ & $0,06 \%$ & $0,06 \%$ & Limosin & PE \\
\hline 3 & $05 / 2001$ & NI & $2 d$ & NI & $\mathrm{NI}$ & Charolês & $\mathrm{P}$ \\
\hline 4 & $06 / 2001$ & 80 & $6 \mathrm{~m}$ & $25,00 \%$ & $12,5 \%$ & Cruza (corte) & $\mathrm{P}$ \\
\hline 5 & $06 / 2001$ & 511 & $12 \mathrm{~m}$ & $0,20 \%$ & $0,20 \%$ & Charolês & PE \\
\hline 6 & $12 / 2001$ & NI & $6 \mathrm{~m}$ & NI & NI & Jersey & $\mathrm{PE}+$ \\
\hline 7 & $12 / 2001$ & 378 & $80 d$ & $1,85 \%$ & $1,85 \%$ & Hereford & $\mathrm{P}$ \\
\hline 8 & $06 / 2002$ & 750 & $6 \mathrm{~m}$ & $1,33 \%$ & $1,33 \%$ & Cruza (corte) & PE \\
\hline 9 & $07 / 2002$ & 50 & $3 m$ & $8 \%$ & $6 \%$ & Jersey & PE \\
\hline 10 & $07 / 2002$ & 160 & $3 d$ & $0,63 \%$ & $0,63 \%$ & Jersey & $\mathrm{P}$ \\
\hline 11 & $09 / 2002$ & 70 & $7 d$ & $7,14 \%$ & $7,14 \%$ & Devon & PE \\
\hline 12 & $11 / 2002$ & 4 & $6 \mathrm{~m}$ & $100 \%$ & $25 \%$ & Holandês & $\mathrm{P}$ \\
\hline 13 & $04 / 2003$ & 63 & $9 \mathrm{~m}$ & $3,17 \%$ & $3,17 \%$ & $\mathrm{Ni}$ & $\mathrm{P}$ \\
\hline 14 & $07 / 2003$ & NI & $6 \mathrm{~m}$ & NI & NI & Cruza (corte) & PE \\
\hline 15 & $11 / 2004$ & NI & $1 \mathrm{~m}$ & NI & NI & Holandês & $\mathrm{P}$ \\
\hline 16 & $05 / 2005$ & 128 & $6 \mathrm{~m}$ & $39,06 \%$ & $3,12 \%$ & Angus & $\mathrm{PE}+$ \\
\hline 17 & $01 / 2006$ & 150 & $1-3 m$ & $26,70 \%$ & $12,67 \%$ & Holandês & $\mathrm{PE}+$ \\
\hline 18 & $01 / 2007$ & 26 & bezerro & $38,46 \%$ & $34,61 \%$ & Holandês & $\mathrm{P}$ \\
\hline 19 & $10 / 2007$ & 700 & $12 \mathrm{~m}$ & $14,28 \%$ & $11,42 \%$ & Braford & PE \\
\hline 20 & $04 / 2008$ & 45 & $3 \mathrm{~m}$ & $2,22 \%$ & $2,22 \%$ & Holandês & $\mathrm{P}$ \\
\hline 21 & $09 / 2008$ & 16 & $2 \mathrm{~m}$ & $12,5 \%$ & $12,5 \%$ & Holandês & $\mathrm{P}$ \\
\hline 22 & $11 / 2008$ & 350 & $2 \mathrm{~m}$ & $0,28 \%$ & $0,28 \%$ & $\mathrm{Ni}$ & $\mathrm{PE}+$ \\
\hline 23 & $10 / 2009$ & NI & bezerro & NI & $\mathrm{NI}$ & Holandês & $\mathrm{PE}+$ \\
\hline 24 & $08 / 2010$ & 450 & $12 \mathrm{~m}$ & $1,11 \%$ & $0,44 \%$ & Montana & PE \\
\hline 25 & $09 / 2010$ & 140 & $12 \mathrm{~m}$ & $5 \%$ & $3,57 \%$ & Montana & PE \\
\hline 26 & $03 / 2011$ & 110 & $1 \mathrm{~m}$ & $0,9 \%$ & $0,9 \%$ & Jersey & $\mathrm{P}$ \\
\hline 27 & $04 / 2011$ & 150 & $3 \mathrm{~m}$ & $2,66 \%$ & $2,66 \%$ & Holandês & $\mathrm{P}$ \\
\hline 28 & $04 / 2011$ & 10 & $8 m$ & $20 \%$ & $20 \%$ & Holandês & $\mathrm{P}$ \\
\hline 29 & $06 / 2011$ & 250 & $1 \mathrm{~m}$ & $8,00 \%$ & $0,4 \%$ & Holandês & $\mathrm{PE}+$ \\
\hline 30 & $08 / 2011$ & 78 & $9 m$ & $1,28 \%$ & $1,28 \%$ & Holandês & $\mathrm{P}$ \\
\hline 31 & $10 / 2011$ & 12 & $2 \mathrm{~m}$ & $8,33 \%$ & $8,33 \%$ & Jersey & $\mathrm{P}$ \\
\hline 32 & $11 / 2011$ & 10 & $15 \mathrm{~d}$ & $10 \%$ & $10 \%$ & Jersey & $\mathrm{P}$ \\
\hline 33 & $12 / 2011$ & 78 & $5 \mathrm{~m}$ & $1,28 \%$ & $1,28 \%$ & Jersey & PE \\
\hline
\end{tabular}

$\mathrm{m}$ = meses; $\mathrm{d}=$ dias; $\mathrm{P}=$ pneumonia inespecífica; $\mathrm{PE}=$ pneumonia enzoótica; $\mathrm{NI}=$ não informado; + marcação positiva na imuno-histoquímica para o vírus sincicial respiratório bovino.

bovinos afetados não estava especificada no protocolo $(5,8 \%)$.

Os sinais clínicos observados nos bovinos encaminhados vivos ao LRD caracterizaram-se por dispneia, emagrecimento, apatia, tremores, bruxismo, desidratação, respiração ruidosa, corrimento nasal seroso ou mucopurulento, decúbito e morte. Em alguns casos os animais afetados apresentavam dificuldade respiratória ao serem movimentados; em outros apresentavam o pescoço estendido e a língua para fora da cavidade oral evidenciando severa dificuldade respiratória (Fig.1B) ou com a boca aberta e salivação acentuada (Fig.1C), e eventualmente tosse (Fig.1D). Em alguns casos os sinais respiratórios eram discretos e podiam passar despercebidos, mas os bovinos afetados apresentavam outros sinais como fraqueza, diarreia e emagrecimento.

As lesões macroscópicas observadas nos animais afetados foram agrupadas conforme o que segue: 1) pneumonia ou broncopneumonia lobular afetando as regiões crânio-ventrais dos lobos pulmonares, principalmente os lobos cardíaco e apical e caracterizadas por áreas de consolidação vermelho-escuras (Fig.2A-C) acompanhadas por edema e enfisema (Fig.2D), presença de fibrina na superfície do órgão ou presença de exsudato purulento por vezes formando abscessos distribuídos pelo parênquima; e 2) pneumonia intersticial com distribuição difusa caracterizada por impressão das costelas e pulmão sem colabamento após a abertura da cavidade torácica, com edema e enfisema acentuados (Fig.2B). Ambas as lesões podiam ser observadas concomitantemente.

Em seis casos houve crescimento bacteriano nas culturas realizadas em ágar sangue ovino 5\% e ágar MacConkey, sendo que em dois, o agente isolado foi Pasteurella spp.; em um o agente foi Pasteurella multocida; em outro Escherichia coli; em outro houve crescimento de Branhamella catarralis, e em um de Pseudomonas spp. Em seis casos não foi realizada a cultura microbiológica e um material chegou ao laboratório formolizado não permitindo a realização da cultura. Em quatro casos não houve crescimento bacteriano na cultura realizada.

Histologicamente, as lesões pulmonares eram variáveis. Dos 17 casos suspeitos de pneumonia enzoótica em 14 havia lesões de broncopneumonia necrossupurativa difusa (Fig.3A) com hiperplasia de pneumócitos tipo II e edema intersticial e alveolar (Fig.3B). Em 11 destes casos havia, também, presença de células sinciciais (Fig, 3C). Havia, também, na maioria dos casos, deposição de fibrina nos alvéolos e em dois casos presença de células em grão de aveia 

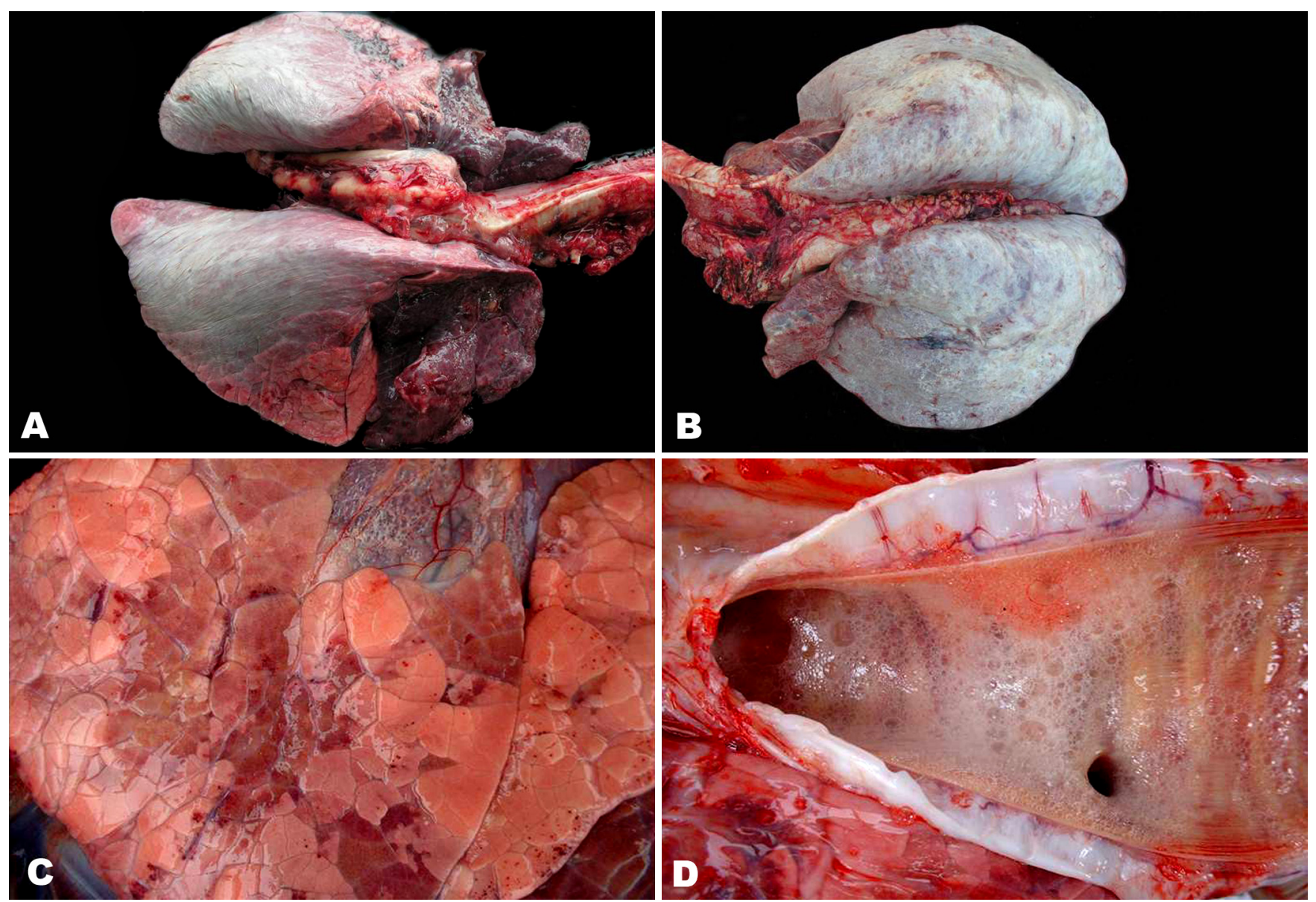

Fig.2. (A) Pulmão de bezerro (surto 18) com diagnóstico de pneumonia enzoótica por vírus sincicial respiratório bovino mostrando consolidação das porções ventrais dos lobos cardíaco e apical. (B) Pulmão de bezerro com pneumonia enzoótica mostrando consolidação das porções ventrais dos lobos cardíaco e apical. A porção dorsal dos lobos diafragmáticos está armada, com impressão das costelas. (C) Lobos pulmonares consolidados de coloração avermelhada alternados com lobos normais dando um aspecto moteado ao parênquima. (D) Edema pulmonar evidenciado pela presença de espuma na traqueia.

distribuídas pelos alvéolos e septos alveolares espessados (Fig.3D). Em quatro destes 14 casos as lesões eram moderadas observando-se bronquiolite e proliferação de pneumócitos tipo II e pneumonia intersticial, sendo que em três destes havia células sinciciais. De três casos em que não havia blocos de parafina para reavaliação das lesões em um a descrição era de broncopneumonia necrossupurativa difusa acentuada com infecção secundária por Pseudomonas spp. Em dois casos havia apenas o diagnóstico de pneumonia enzoótica por BRSV no protocolo.

Dos 14 casos consistentes com pneumonia enzoótica (FIg.4A) submetidos à técnica imuno-histoquímica para detecção do BRSV, sete tiveram marcação positiva (Fig.4B) e não houve marcação positiva para BPIV-3 em nenhum dos casos.

\section{DISCUSSÃO}

0 presente trabalho demonstrou que dentre as enfermidades pulmonares de bezerros até um ano de idade a pneumonia enzoótica tem importante papel como causa de mortalidade. As pneumonias de um modo geral foram mais frequentes em bovinos leiteiros. Isto ocorre, provavelmente, devido ao manejo utilizado como o desmame precoce dos bezerros, o confinamento e outras causas de estresse a que os bovinos, especialmente das raças leiteiras, são submetidos nos primeiros meses de vida. Em outros países a doença é muito frequente em bovinos de corte confinados (Gagea et al. 2006a, 2006b, Snowder et al. 2006, Booker et al. 2008, Fulton et al. 2009, Lorenz et al. 2011), sugerindo que a doença está relacionada ao manejo e não a aptidão dos animais para produção de leite ou carne.

Nos surtos observados a morbidade foi muito variável chegando a $100 \%$ em um surto em bovinos de leite. A mortalidade variou de 0,06\%-34,6\%. Em outros países, como os Estados Unidos tem sido observada morbidade de até $14,4 \%$ e mortalidade de $44 \%-67 \%$ em bovinos de corte criados confinados (Snowder et al. 2006, Lorenz et al. 2011). No Canadá a mortalidade é variável de 10\%-66\% (Gagea et al. 2006a).

Tem sido mencionado que bezerros lactentes criados a campo estão submetidos a baixo risco de sofrer pneumonia, porém surtos podem ocorrer se condições climáticas extremas surgem repentinamente (Lorenz et al. 2011). Deve-se ressaltar que o clima no Rio Grande do Sul é temperado, sujeito a variações abruptas de temperatura em todas as estações do ano, devido a influências de fenômenos 

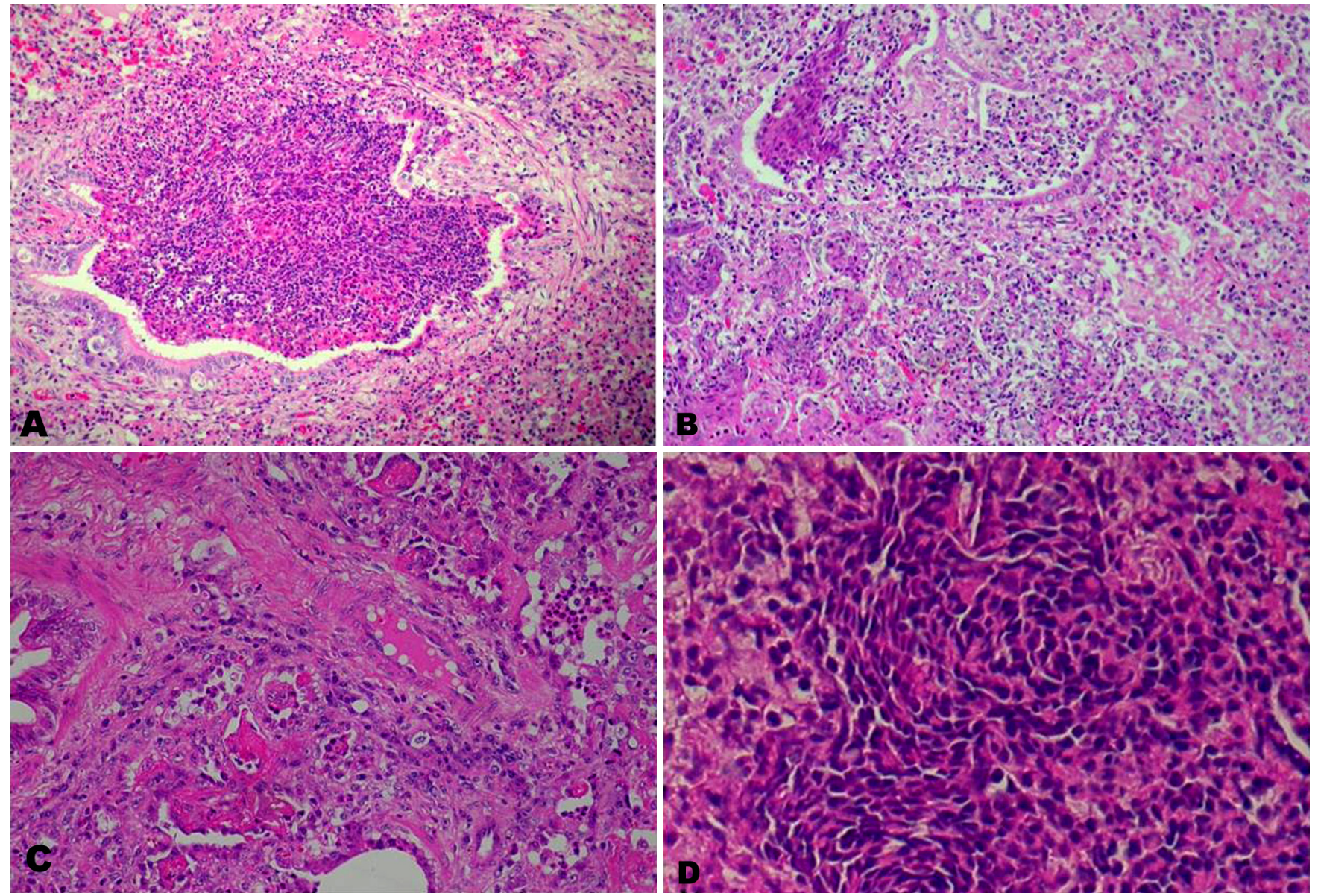

Fig.3. Pneumonia enzoótica em bezerros. (A) Broncopneumonia necrossupurativa com infiltrado polimorfonuclear no interior de um bronquíolo e no parênquima pulmonar adjacente. HE, obj.10x. (B) Pneumonia intersticial com hiperplasia de pneumócitos tipo II. HE, obj.10x. (C) Há células sinciciais necróticas em meio a infiltrado inflamatório no parênquima pulmonar. HE, obj.10x. (D) Presença de células em grão de aveia características de infecção secundária por Mannheimia haemolytica. HE, obj.40x.
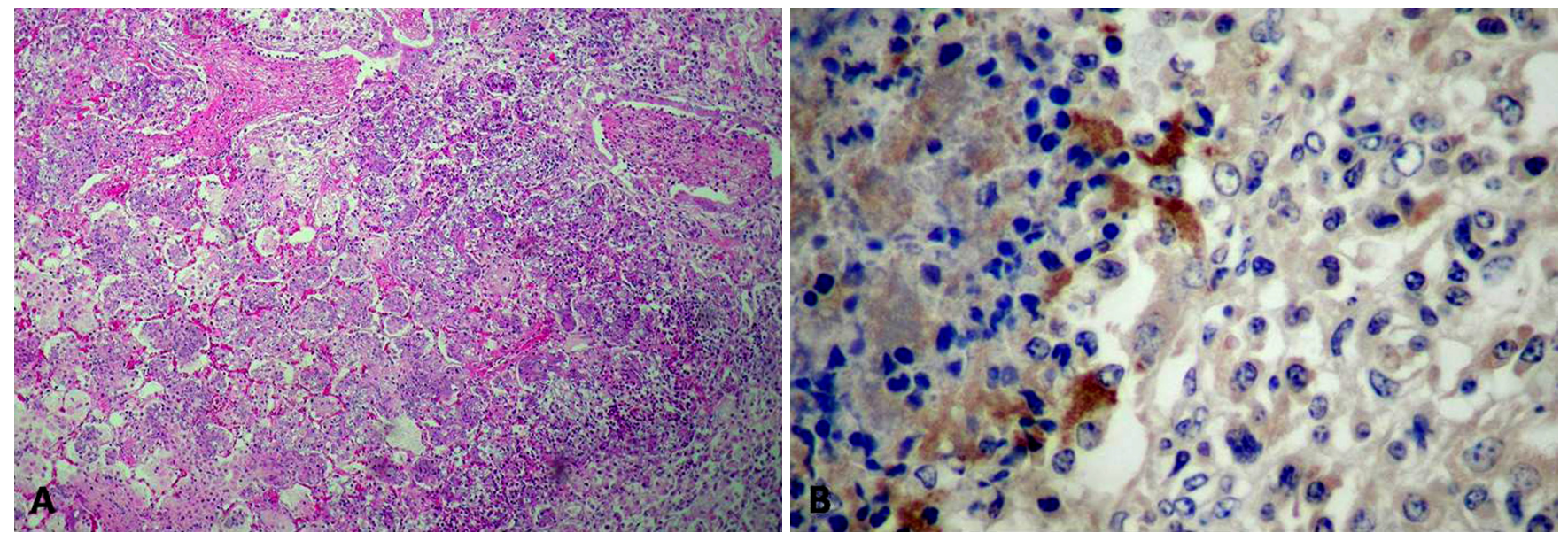

Fig.4. Pneumonia enzoótica. (A) Lesões pulmonares características com infiltrado inflamatório misto intersticial e intrabronquiolar e edema alveolar. HE, obj.10x. (B) Imuno-histoquímica positiva para BRSV em células epiteliais bronquiolares do mesmo caso. HE, obj.40x.

climáticos como El Niño e La Niña favorecendo a ocorrência da doença (Firpo et al. 2012). Um surto de pneumonia enzoótica causado por BRSV em bovinos de corte criados extensivamente foi diagnosticado na primavera/verão no Rio Grande do Sul (Driemeier et al. 1997), porém não foram mencionadas as condições climáticas por ocasião do surto. No presente estudo não houve diferença notável na ocorrência da doença entre as estações do ano.

A faixa etária com o maior número de casos de enfermidades respiratórias foi de bezerros de 1 a 3 meses. É mencionado que BRSV é importante causa de surtos agudos de pneumonia enzoótica em bovinos leiteiros e de corte de 
duas semanas a 5 meses de idade com pico de incidência na faixa etária de 1 a 3 meses (Caswell \& Williams 2007).

As lesões macroscópicas observadas na maioria dos casos estudados (15/33) eram lesões típicas de broncopneumonia afetando as áreas crânio-ventrais pulmonares e em alguns casos também, as áreas dorso-caudais e pneumonia intersticial. Estas lesões têm sido descritas em casos de pneumonia enzoótica por BRSV (Caswell \& Williams 2007). Nos casos em que houve marcação positiva para BRSV havia broncopneumonia necrossupurativa com presença de células sinciciais principalmente no epitélio dos bronquíolos e no interior de alvéolos. Embora não tenha ocorrido imunomarcação em todos os casos suspeitos de pneumonia enzoótica por BRSV não pode afirmar-se que a doença não tenha sido causada por este virus. Em outras causas virais de pneumonia enzoótica como a infecção pelo virus BPIV-3 as células sinciciais localizam-se preferencialmente nos alvéolos e são menos frequentes do que nos casos de pneumonia enzoótica por BRSV (Caswell \& Williams 2007). No presente estudo não houve marcação positiva para o BPIV-3 na imuno-histoquímica em nenhum dos casos estudados. Tem sido mencionado que em alguns casos não há antígeno em níveis detectáveis no tecido para haver imunomarcação (Webster et al. 2010). Além disso, a perda da imunorreatividade por muitos antígenos está relacionada principalmente ao tempo de fixação, a temperatura dos procedimentos subsequentes e a exposição à luz (Ramos-Vara \& Beissenherz 2000).

Os resultados deste trabalho demonstram que as pneumonias são importantes causas de morte em bovinos jovens na região de abrangência do LRD. Deve ser destacado que a pneumonia enzoótica devido à infecção pelo BRSV é importante tanto em bovinos de corte como de leite, independentemente da forma de criação. A tendência de aumento na prática de criação em confinamento ou semi-confinamento poderá ter como consequência o aumento da mortalidade por esta enfermidade na região a exemplo do que ocorre em outros países cuja prática de criação em confinamento é comumente utilizada.

\section{REFERÊNCIAS}

Assis-Brasil N.D., Marcolongo-Pereira C., Hinnah F.L., Ladeira S.R.L., Sallis E.S.V., Grecco F.B. \& Schild A.L. 2013. Enfermidades diagnosticadas em bezerros na região sul do Rio Grande do Sul. Pesq. Vet. Bras. 33(4):423430.

Booker C.W., Abutarbush S.M., Morley P.S., Jim G.K., Pittman T.J., Schunicht O.C., Perrett T., Wildman B.K., Fenton R.K. \& Guichon P.T. 2008. Microbiological and histopathological findings in cases of fatal bovine respiratory disease of feedlot cattle in western Canada. Can. Vet. J. 49:473-481

Caswell J.L. \& Williams K.J. 2007. Respiratory system, p.523-653. In: Maxie M.G. (Ed.), Jubb, Kennedy, and Palmer's Pathology of Domestic Animals. Vol.2. $5^{\text {th }}$ ed. Saunders Elsevier, Philadelphia.

Driemeier D., Gomes M.J.P., Moojen V., Arns C.W., Vogg G., Kessler L. \& Costa U.M. 1997. Manifestação clínico-patológica de infecção natural pelo Vírus Respiratório Sincicial Bovino (BRSV) em bovinos de criação extensiva no Rio Grande do Sul, Brasil. Pesq. Vet. Bras. 17(2):77-81.

Driemeier D. \& Moojen V. 2007. Complexo respiratório bovino, p. 490-496. In: Riet-Correa F., Schild A.L., Lemos R.A.A. \& Borges J.R J. (Eds), Doenças de Ruminantes e Eqüídeos. Vol.1. 3aㅡ ed. Pallotti, Santa Maria.

Firpo M.A.F., Sansigolo C.A. \& Assis S.V. 2012. Climatologia e variabilidade sazonal do número de ondas de calor e de frio no Rio Grande do Sul associadas ao ENOS. Revta Bras. Meteorol. 27(1):95-106.

Flores E.F., Weiblen R., Botton S.A., Medeiros M., Irigoyen L.F., Driemeier D., Schuch L.F. \& Moraes M.S. 2000. A retrospective search for bovine respirator y syncytial virus (BRSV) antigens in histological specimens by immunofluorescence and immunohistochemistry. Pesq. Vet. Bras. 20(4):139-143.

Fulton R.W., Blood K.S., Panciera R.J., Payton M.E., Ridpath J.F., Confer A.W., Saliki J.T., Burge L.T., Welsh R.D., Johnson B.J. \& Reck A. 2009. Lung pathology and infectious agents in fatal feddlot pneumonias and relationship with mortality, disease onset, and treatments. J. Vet Diagn. Invest. 21:464-477.

Gagea M.I., Bateman K.G., Dreumel T.V., McEwen B.J., Carman S., Archambault M., Shanahan R.A. \& Caswell J.L. 2006a. Diseases ans pathogens associated with mortality in Ontario beef feedlots. J. Vet. Diagn. Invest. 18:18-28.

Gagea M.I., Kenneth G.B., Shanahan R.A., Dreumel T.V., McEwen B.J., Carman S., Archambault M., Shanahan R.A. \& Caswell J.L. 2006b. Naturally occurring Mycoplasma bovis-associated pneumonia and polyarthritis in feedlot beef calves. J. Vet. Diagn. Invest. 18:29-40.

Loneragan G.H., Dargatz D.A., Morley P.S. \& Smith M.A. 2001. Trends in mortality ratios among cattle in US feedlots. J. Am. Vet. Med. Assoc. 219(8):1122-1127.

Lorenz I., Earley B., Gilmore J., Hogan I., Kennedy E. \& More S.J. 2011. Calf health from birth to weaning. III. Housing and management of calf pneumonia. Irish Vet. J. 64(14):1-9.

Peixoto P.V., Mota R.A., Brito M.F., Corbellini L.G., Driemeier D. \& Souza M.I. 2000. Infecção natural pelo virus respiratório sincicial bovino (BRSV) no estado de Alagoas. Pesq. Vet. Bras. 20(4):171-175.

Ramos-Vara J.A. \& Beissenherz M.E. 2000. Optimization of imunohistochemical methods using two different antigen retrieval methods on formalin-fixed, parafin-embedded tissues: experience with 63 markers. J. Vet. Diagn. Invest. 12:307-311.

Snowder G.D., Van Vleck L.D., Cundiff L.V. \& Bennett G.L. 2006. Bovine respiratory disease in feedlot cattle: Environmental, genetic and economic factors. J. Anim. Sci. 84:1999-2008. doi: 10.2527/jas.2006-046.

Webster J.D., Miller M.A., DuSold D. \& Ramos-Vara J. 2010. Effects of prolonged formalin fixation on the immunohistochemical detection of infectious agents in formalin-fixed, paraffin-embedded tissues. Vet. Pathol. 47(3):529-535. 